\title{
Healthy Neighbourhoods: Health Promotion and Prevention in Urban Neighbourhoods
}

\section{Joachim Westenhöfer ${ }^{1}$, Johanna Buchcik ${ }^{1}$, Jana Borutta ${ }^{1}$}

${ }^{1}$ Competence Center Health, Department Health Sciences, Hamburg University of Applied Sciences, Germany

\begin{abstract}
Background: Maintaining good quality of life in urban neighbourhoods is one of the biggest challenges. The project "Healthy Neighbourhoods - Health Promotion and Prevention in Urban Neighbourhoods" (07/2017 - 12/2020) aims to describe and improve health and quality of life of citizens living in neighbourhoods with different socio-economic statuses.

Method: To examine the possible association between socio-economic status (SES) and health, a cross-sectional survey in six urban neighbourhoods with "very low", "low", "middle" and "high" social statuses was conducted.

Results: In July 2019, a preliminary dataset with 700 respondents was available for analysis. Analyses of covariance showed that physical healthrelated quality of life was impaired in neighbourhoods with very lower SES, while body mass index was increased. There were no significant differences in mental health-related quality of life.

Discussion The results confirm that neighbourhoods with low and very low SES should be primary targets for interventions of health promotion and prevention. To ensure a participative approach for the development of such interventions, the results will be presented to and discussed with residents and other relevant stakeholders of the target neighbourhoods in order to identify the appropriate interventions policies.
\end{abstract}

Keywords: health promotion, urban neighbourhoods, health-related quality of life, . 


\section{Introduction}

Urbanization is one of the global megatrends that charactize the current development of mankind. At the beginning of the $20^{\text {th }}$ century, only about 10 percent of the world's population were living in urban areas. In 2015, this percentage had increased to about $54 \%$, and it is predicted to increase to $60 \%$ in 2030 and to $66 \%$ by 2050 (World Health Organization \& UN Habitat, 2016, p. 14). Ensuring and enhancing health and well-being of the population living in urban areas is an important and demanding challenge. The neighbourhoods in which people live are important determinants of health and well-being. They include several elements and processes and the interaction between them, as illustrated in figure 1 (Barton \& Grant, 2006).

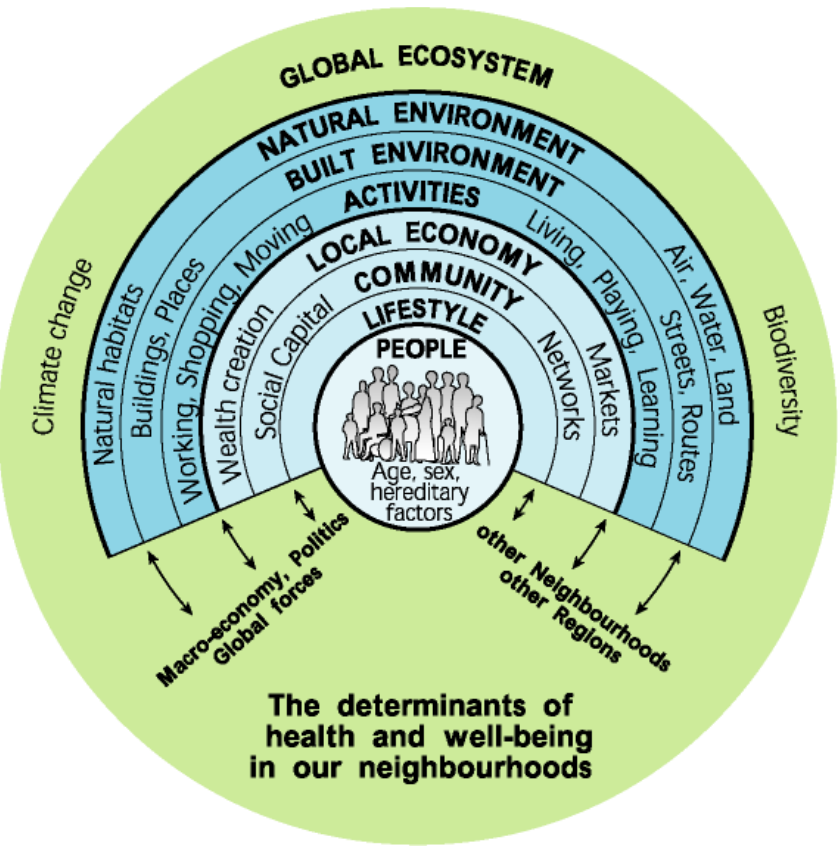

Figure 1. Determinants of health in neighbourhoods. Source:Barton \& Grant (2006) inspired by Dahlgren \& Whitehead (1991)

Neighbourhoods that are socio-economically disadvantaged often present complex problems of the social, economic, infrastructural and built environment. Often, people with low socio-economic ressources are living in such neighbourhoods: unemployed, mirgants, single parent families and large families. Often there is a lack of recreational facilities, play grounds and opportunities for physical activity. In addition,environmental health risks such as high traffic load, heightend burden of noice and pollution and poor safety levels are often present in such neighbourhoods (Böhme, Kliemke, Reimann, \& Süß, 2012). Therefor such 
neighbourhoods should be a primary target of health promotion interventions, not only covering behavioural approaches but also environmental interventions.

The project "Healthy Neighbourhoods" in Hamburg aims to develop and evaluate such health promoting interventions in two socially deprived neighbourhoods. The development if the interventions is informed by (1) a survey of attitiudes, perceptions and behaviours of residents and comparison to other less deprived neighbourhoods, (2) structured audits of environmental characteristics of the neigbourhoods and available statistical data, (3) analysis of statutory health insurance data, (4) a qualitative analysis with stakeholders of other local health promotion and prevention projects, (5) a systematic review of community intervention projects, and (6) a participatory process involving stakeholders and residents in the intervention neighbourhoods.

The present paper reports on a preliminary interim analysis of the first of the six mentioned elements, the residents' survey in 6 urban neighbourhoods of Hamburg. The purpose of the survey is to inform the development of interventions by identifying needs, analyzing the relation between socio-economic status of neighbourhoods, modifyable protective and risk factors for health and to build the basis for the future evaluation of the interventions. The survey was developed according to the model outlined in figure 2. We assume that there is a complex interaction between the perceived characteristics of the neighbourhoods and the residents' health behavior which together influence their health and well-being. Therefor, a questionnaire was developed that includes an assessment of walkability, community sense, nutrition, physical activity, alcohol and tobacco consumption, resilience, health-related quality of life as well as the socio-economic and the socio-demographic status. However, the present paper will be limited to results related to some indicators of health and the socio-economic status of the neighbourhoods.

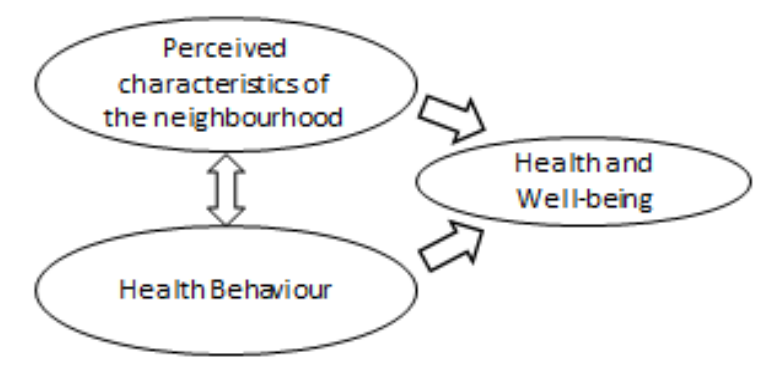

Figure 2.Underlying model for the development of the residents' survey 


\section{Methods}

The present study took place in the City of Hamburg, Germany. Hamburg is devided in 941 statistical districts which are areas with up to 6000 inhabitants. Hamburg has set up a process which is called social monitoring in order to identify neighbourhoods with a need for further urban development. Therefor statistical districts are grouped into 4 levels of socio-economic status SES (very low, low, middle and high) based on 7 indicators (Freie und Hansestadt Hamburg, 2018): (1) children and adolescents with migration background; (2) children of single parent families; (3) recipients of basic social security benefits; (4) unemployed; (5) children receiving basic social security benefits; (6) elderly persons (65 years and older) receiving basic social security benefits and (7) portion of pupils leaving schools with low educational levels.

For the current project we randomly selected 6 statistical districts as investigation areas which fulfilled the following criteria: (1) 2000 or more inhabitants and (2) no recent health related projects (with an annual budget of more than $10,000 €$ in the last 3 years), and (3) two areas with a very low SES, two with low SES, one with middle and one with high SES according to the social monitoring report of 2017 (Freie und Hansestadt Hamburg, 2018). For each of these 6 neighbourhoods a list of randomly selected 800 subjects was retrieved from the city's residents' registration office. These subjects were invited to participate in a standardized face to face interview (30 - 40 minutes) or to fill out the interview questionnaire themselfes if they preferred. Participant gave written informed consent and were paid $10 €$ in compensation for their time and effort. The study protocol was approved by the ethical committee of the Compentence Center Health of the Hamburg University of Applied Sciences. The survey was conducted between May 2018 and July 2019.

The questionnaire included among other sections (see figure 2) questions on sociodemographic data, self-reported weight and height, and the Short-Form SF12, a standardized and well validated instrument to assess health-related quality of life (HRQoL) (Ware, Kosinski, \& Keller, 1996; Morfeld, Kirchberger, \& Bullinger, 2011). From the SF12 two component scores are computed, one measuring physical HRQoL, the other mental HRQoL. Both scores are standardized to a population mean of 50 with a standard deviation of 10. Body Mass Index BMI was calculated from self-reported weight and height using the standard formula $B M I=\frac{\mathrm{kg}}{\mathrm{m}^{2}}$. Migration background is a dichotomous categorial variable with the value yes $=1$ if one of the parents was born in a country other than Germany, and no $=0$ if both parents were born in Germany.

Statistical analyses were computed using IBM SPSS Version 25. Descriptive statistics are reported as means \pm standard deviations for interval scaled variables and percentages for categorial variables. Differences between the 6 urban neighbourhoods were analysed using 
analyses of variance for age and a chi-square tests for sex and migration background. For HRQoL and BMI as dependent variables, analyses of covariance using sex, age and migration background as covariates were computed. Estimated marginal means are shown together with $95 \%$ confidence intervals. Only male and female subjects were included in analyses which involved sex. In addition, since several subjects did not answer all questions, the number of subjects in the reported analyses is usually less than 700 , as we used the listwise exclusion of missing data, e.g. we excluded subjects if the had missing data on one or more of the variables of the respective analysis.

\section{Results}

The current dataset comprises 700 subjects. $389(55.6 \%)$ are females, $303(43,3 \%)$ are males, 2 are divers, and 6 subjects did not disclose their sex. The distribution of sex did not differ significantly between the 6 neighbourhoods (Chi-square $=6.3$; $\mathrm{df}=5 ; \mathrm{p}=0.28$ ). However, average age and the portion of subjects with migration background differed significantly between the 6 neighbourhoods (age: $\mathrm{F}=21.8 ; \mathrm{df}=5 / 642 ; \mathrm{p}<0.001$; migration background: Chi-square $=105,4 ; \mathrm{df}=5 ; \mathrm{p}<0.001)($ see table 1$)$.

Table 1. This is the style for table captions (Times New Roman 9pt bold). Table captions should appear above tables.

\begin{tabular}{|l|c|c|c|c|}
\hline Neighbourhood & $\begin{array}{c}\text { Number of } \\
\text { subjects for } \\
\text { age/migration } \\
\text { background }\end{array}$ & $\begin{array}{c}\text { Neighbourhood } \\
\text { Socio-Economic } \\
\text { Status }\end{array}$ & $\begin{array}{c}\text { Age mean } \pm \\
\text { standard deviation }\end{array}$ & $\begin{array}{c}\text { Percentage of } \\
\text { subjects with } \\
\text { migration } \\
\text { background }\end{array}$ \\
\hline Wilhelmsburg & $52 / 73$ & Very low & $39.1 \pm 15.3$ & $79.7 \%$ \\
\hline Rahlstedt & $121 / 126$ & Very low & $50.9 \pm 14.0$ & $24.6 \%$ \\
\hline Hamm & $123 / 124$ & Low & $40.7 \pm 16.8$ & $37.4 \%$ \\
\hline Lohbrügge & $102 / 107$ & Low & $45.2 \pm 16.9$ & $51.0 \%$ \\
\hline Stellingen & $132 / 138$ & Middle & $43.2 \pm 13.8$ & $41.8 \%$ \\
\hline Sasel & $118 / 124$ & High & $57.8 \pm 15.8$ & $10.0 \%$ \\
\hline Total & $648 / 692$ & & $46.8 \pm 16.6$ & $37.2 \%$ \\
\hline
\end{tabular}

The average score for physical component of health-related quality of life differed significantly between the 6 neighbourhoods after adjustment for sex, age and migration background $(\mathrm{F}=5.6 ; \mathrm{df}=5 / 550 ; \mathrm{p}<0.001$; partial eta-square=0.05). As illustrated in Figure 1 , the average physical health-related quality of life is lower in the neighbourhoods with 
lower SES, particularly in those with very low SES, as compared to neighbourhoods with higher SES. The corresponds with the tendency for average BMI. Neighbourhoods with very low SES show higher average BMI than neighbourhoods with higher SES (Figure 2). Average BMI, adjusted for sex, age and migration background is significantly different between the 6 neighbourhoods $(\mathrm{F}=5.7 ; \mathrm{df}=5 / 550 ; \mathrm{p}<0.001$; partial eta-square=0.05). In contrast to these indicators of physical health, the average score of the mental health-related quality of life, adjusted for sex, age and migration status, did not differ significantly between the 6 neighbourhoods $(\mathrm{F}=1.5 ; \mathrm{df}=5 / 550 ; \mathrm{p}=0.173$; partial eta-squared $=0.01)$

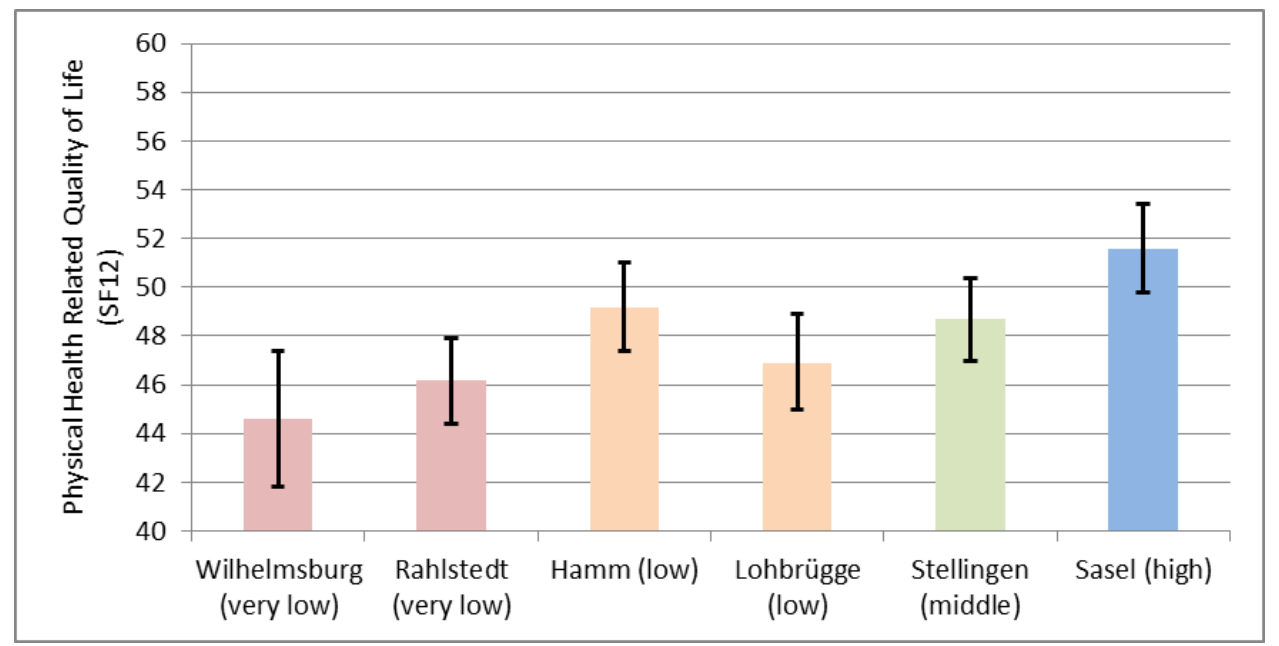

Figure 3. Average score of physical health-related quality of life (SF12) (with 95\% confidence intervals) adjusted for sex, age and migration background.

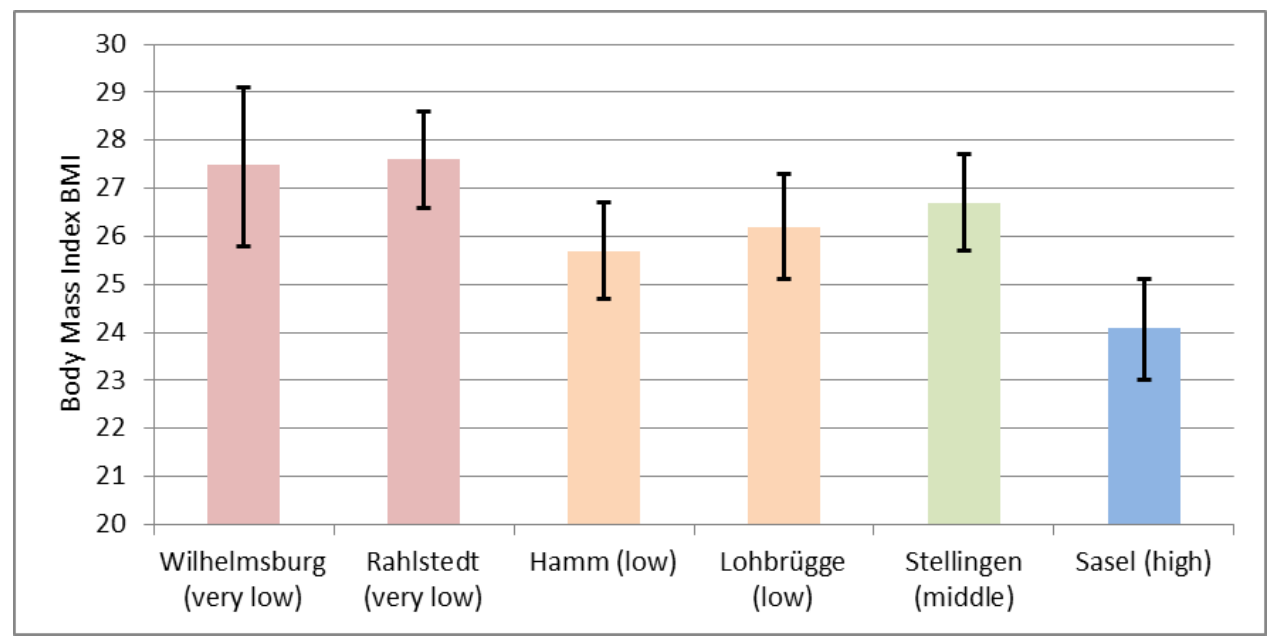

Figure 4. Average Body Mass Index) (with 95\% confidence intervals) adjusted for sex, age and migration background. 


\section{Discussion}

These preliminary interim results of the present study indicate that the socioeconomic status of urban neighbourhoods in Hamburg is associated with differences in the health of its inhabitants. Lower socioeconomic status is associated with indicators of poorer physical health, more specifically lower physical health-related quality of life and higher body mass index. In contrast to these relationships the mental health-related quality of life did not differ significantly between neighbourhoods with different socio-economic status.

The present study and the presented results have some limitations which are important to note. First of all, we are presenting results from a cross-sectional study. Therefor, the reported associations are correlations, and causal interpretations are not justified. Secondly, we are presenting preliminary results from an interim analysis of incomplete data, as the data collection, data entry and data clearance was still in progress at the time of writing. Thus, results might change, when the full dataset becomes available. However, the final dataset will presumably add less than a 100 additional subjects to the 700 subjects in the current analyses. Third, we are presenting results on only a very limited set of variables. Although we have adjusted our analyses for important determinants such as sex, age and migration background, we cannot exclude the possibility that other effect modifiers or confounders are present that impair the validity of the results.

Despite the limitations of the present study, it might be expected that these results can be generalized to other cities as well. In summary, the presented results confirm that the physical health of the residents in neighbourhoods with low socio-economic status is impaired as compared to better off neighbourhoods, and that neighbourhoods with low socio-economic status should be an important focus of intervention for health promotion and disease prevention.

As a next step, the results will be presented to and discussed with residents and other relevant stakeholders of the target neighbourhoods in order to start a participatory process to identify appropriate and relevant interventions policies for health promotion and prevention in the setting of urban neighbourhoods.

\section{References}

Barton, H., \& Grant, M. (2006). A health map for the local human habitat. Journal of the Royal Society for the Promotion of Public Health, 126(6), 252-261. https://doi.org/10.1177/1466424006070466 
Böhme, C., Kliemke, C., Reimann, B., \& Süß, W. (2012). Handbuch Stadtplanung und Gesundheit. Bern: Huber.

Dahlgren, G., \& Whitehead, M. (1991). Policies and strategies to promote social equity in health. Retrieved from http://s2.medicina.uady.mx/observatorio/docs/eq/li/Eq_2007_Li_Dahlgren.pdf

Freie und Hansestadt Hamburg (Ed.). (2018, January). Sozialmonitoring Integrierte Stadtentwicklung. Bericht 2017. Retrieved from https://www.hamburg.de/contentblob/10271310/ff3ff757e66542aed8c9294fe32de 604/data/d-sozialmonitoring-bericht-2017.pdf

Morfeld, M., Kirchberger, I., \& Bullinger, M. (2011). SF-36. Fragebogen zum Gesundheitszustand. (2.). Göttingen: Hogrefe.

Ware, J., Kosinski, M., \& Keller, S. D. (1996). A 12-Item Short-Form Health Survey: Construction of scales and preliminary tests of reliability and validity. Medical Care, 34(3), 220-233.

World Health Organization, \& UN Habitat. (2016). Global report on urban health: Equitable, healthier cities for sustainable development. Retrieved from https://apps.who.int/iris/handle/10665/204715 